\title{
Um diálogo entre o Pensamento Descolonial e a Antropologia Jurídica: elementos para o resgate dos saberes jurídicos subalternizados
}

\author{
Thais Luzia Colaço ${ }^{1}$ \\ Eloise da Silveira Petter Damázio ${ }^{2}$
}

Resumo: O presente artigo propõe uma abordagem sobre o estudo da Antropologia Jurídica associado à perspectiva da descolonialidade com o objetivo de demonstrar como essa associação contribui para uma descolonialidade do poder e do saber no âmbito jurídico. A reflexão sobre a colonialidade se dá a partir do Pensamento Descolonial, o qual proporciona novas perspectivas para o mundo das ciências sociais e das humanas, configurando "outros lugares" para a produção de conhecimento. Por fim, apresenta uma análise da Antropologia Jurídica com a intenção de verificar como ela, associada aos estudos da descolonialidade, significa não somente uma ferramenta que possibilita a crítica dos discursos dominantes, mas também representa uma alternativa para falar sobre "mundos e conhecimentos de outra maneira".

Palavras-chave: Pensamento Descolonial. Antropologia Jurídica. Colonialidade do saber.

\begin{abstract}
The present paper proposes an approach about the study of the Legal Anthropology associated with the perpective of the decoloniality, the objective is to describe how this association contributes to a decoloniality of the power and the knowledge in the legal sphere. The reflection about the coloniality comes from the Decolonial Thinking, this thinking provides new perspectives to the world of the social sciences and humanities, configuring "other places" to the production of knowledge. Finally, it presents an analysis of the Legal Anthropology with the intention to verify how this, associated with the studies about the decoloniality, means not only a tool that enables criticism of the dominant discourse, but also represents an alternative to speak about "worlds and knowledges otherwise".
\end{abstract}

Keywords: Decolonial Thinking. Legal Anthropology. Coloniality of knowledge

1 Graduada em História (1983) e Direito (1992), Mestre em História (1989) e Doutora em Direito (1998) ambos pela Universidade Federal de Santa Catarina (UFSC). Professora dos cursos de graduação e pós-graduação de Direito da Universidade Federal de Santa Catarina. E-mail: thais@ccj.ufsc.br.

2 Possui graduação em Direito pela Universidade do Vale do Itajaí (2005). Atualmente é doutoranda em Direito pela Universidade Federal de Santa Catarina (UFSC) e bolsista do CNPq. E-mail: eloisepetter@yahoo.com.br. 


\section{Introdução}

A noção de "colonialismo" denota uma relação na qual a soberania de um povo reside no poder de outro povo, ou nação. O Pensamento Descolonial desenvolve a ideia de "colonialidade", que se refere a um padrão de poder que emergiu como resultado do colonialismo moderno e tem uma implicação fundamental: a concepção de que o mundo não foi completamente descolonizado. A primeira descolonização iniciada no século XIX foi incompleta, uma vez que se limitou à independência política das periferias. Ao contrário, a segunda descolonização, que diz respeito à categoria descolonialidade, deverá dirigir-se às múltiplas relações, inclusive às epistêmicas, que a primeira descolonização deixou intactas.

A partir da constatação de que a colonialidade persiste, ou que o mundo ainda é colonizado, considera-se urgente uma perspectiva descolonial epistêmica na esfera de todas as ciências, inclusive na esfera jurídica, direcionada principalmente para o resgate dos saberes que foram silenciados pela colonialidade. Nesse sentido, o presente trabalho busca desenvolver um diálogo entre o Pensamento Descolonial e a Antropologia Jurídica.

$\mathrm{O}$ que se objetiva com essa pesquisa é problematizar como esses dois campos de estudos, que se direcionam aos saberes "outros", podem dialogar e, assim, proporcionar elementos que contribuam para o aparecimento dos saberes "outros" subalternizados. Mais especificamente, no sentido de possibilitar um resgate dos saberes jurídicos que foram subalternizados de forma a visibilizá-los no atual cenário acadêmico e, assim, contribuir para uma descolonialidade do saber e do poder.

Para iniciar um possível caminho em direção ao objetivo geral proposto, o presente artigo está dividido em três partes, cada qual correspondendo a um determinado objetivo específico.

Busca-se inicialmente estabelecer e definir os termos-chave do Pensamento Descolonial. Nesse sentido, será indispensável aprofundar os conceitos de colonialidade do poder e também de colonialidade do saber. Resumidamente, o primeiro é entendido como a inter-relação entre modos modernos de dominação e, o segundo, como formas de subalternização dos saberes, na medida em que estes não correspondem aos parâmetros 
dominantes de racionalidade. Feitas essas considerações, será examinada a noção de descolonialidade em sua proposta de oposição radical às colonialidades do poder e do saber, representando, desse modo, uma confrontação com as hierarquias que foram criadas e fortalecidas pela modernidade eurocêntrica, tanto em seu projeto de civilização quanto em suas propostas epistemológicas.

Na segunda parte da pesquisa será descrito um breve panorama histórico sobre a Antropologia e a Antropologia Jurídica, ambas serão consideradas a partir da perspectiva da colonialidade. Trata-se de analisar como esses campos de estudos, inicialmente restritos a uma visão colonial eurocêntrica sobre o "outro", hoje, significam mais um campo de investigação dinâmico do que apenas uma disciplina fechada em si mesma.

Por fim, será considerado como o diálogo entre o Pensamento Descolonial e a Antropologia Jurídica pode contribuir para o desenvolvimento de apontamentos epistemológicos "outros" para a produção de conhecimento no âmbito jurídico. Trata-se de analisar como esse diálogo pode trazer elementos que além de possibilitarem o questionamento dos saberes eurocêntricos também representam uma alternativa de resgate dos saberes jurídicos subalternizados, contribuindo para uma descolonialidade do poder e do saber.

\section{Pensamento Descolonial: colonialidade e descolonialidade}

O Pensamento Descolonial, a partir do projeto modernidade/colonialidade/descolonialidade, realiza uma reflexão sobre as heranças coloniais dos impérios espanhol e português produzidas na América entre os séculos XVI e XX. Procura-se intervir decisivamente na discursividade própria das ciências modernas para configurar outro espaço para a produção de conhecimento, uma forma distinta de pensamento, "um paradigma outro", a possibilidade de falar sobre "[...] mundos e conhecimentos de uma outra maneira." (ESCOBAR, 2005, p. 63-64). ${ }^{3}$

3 Escobar (2005, p. 38) utiliza e define a expressão "Mundos y conocimientos de otro modo" a partir de um duplo aspecto: no sentido de construir políticas a partir da diferença colonial, particularmente no nível do conhecimento e da cultura, e, também, de imaginar e de construir mundos verdadeiramente diferentes. 
Na base da análise descolonial há uma leitura desconstrutiva da visão tradicional da modernidade e uma análise da subalternização cultural e epistêmica das culturas não europeias. Podem ser considerados como autores vinculados a essa corrente, o filósofo Enrique Dussel, o antropólogo e teórico literário e cultural Walter Mignolo, o sociólogo Aníbal Quijano, o filósofo Santiago Castro-Gómez, o sociólogo Ramón Grosfoguel, entre outros.

O termo colonialidade, central nos estudos descoloniais, se distingue do termo colonialismo. Enquanto este diz respeito a uma relação político-econômica entre dois povos, aquele se refere a um padrão de poder que emergiu como resultado do colonialismo moderno e organiza a forma como o trabalho, o conhecimento, a autoridade e as relações intersubjetivas articulam-se entre si. Embora o colonialismo preceda a colonialidade, a colonialidade sobrevive ao colonialismo. Ela se mantém viva nos manuais de aprendizagem, nos critérios para um bom trabalho acadêmico, na cultura, no senso comum, na autoimagem dos povos e nas aspirações dos sujeitos (MALDONADO-TORRES, 2007).

Um conceito importante do projeto modernidade/colonialidade/descolonialidade utilizado para examinar a questão da colonialidade é a categoria "sistema-mundo moderno" criada pelo sociólogo Immanuel Wallerstein. Ele define "sistema-mundo moderno" como o sistema que teve suas origens no século XVI, principalmente em algumas partes da Europa e da América, e que, com o passar do tempo, estendeu-se para todo o mundo. Trata-se de uma "economia-mundo capitalista" (WALLERSTEIN, 2005, p. 40).

A modernidade para muitos é um fenômeno exclusivamente europeu, ou seja, esse processo ocorreria internamente na Europa. Na análise social e filosófica geral afirma-se que a modernidade começa com o cogito cartesiano, um processo exclusivamente europeu que permitiu que a humanidade avançasse racionalmente.

As concepções de Habermas (1990) e Giddens (1991) têm sido particularmente influentes, dando origem a diversos livros sobre modernidade e globalização. 
Nessa perspectiva, a modernidade, segundo Escobar (2003, p. 5556) pode ser caracterizada historicamente, tendo origem temporal e espacialmente identificada: o século XVII, o Norte da Europa, especialmente França, Alemanha e Inglaterra, em torno dos processos da Reforma, do Iluminismo e da Revolução Francesa. Sociologicamente, a modernidade é caracterizada por algumas instituições, como o Estado-nação, e por algumas características básicas, como a reflexividade de si mesma; o feedback contínuo entre o conhecimento de especialistas e a sociedade; o desmembramento da vida social de âmbito local e suas crescentes determinações pelas forças translocais. Culturalmente, a modernidade introduz uma ordem baseada nas construções da razão, do individual, do conhecimento especializado e dos mecanismos administrativos ligados ao Estado. Ordem e razão são vistos como a base para a igualdade e a liberdade. Filosoficamente, pode-se ver a modernidade em termos do surgimento do conceito de "homem" como a base de todo conhecimento e ordem no mundo, separado do natural e do divino. De outro lado, a modernidade é vista em termos do triunfo da metafísica, entendida como uma tendência, e se estende desde Platão e alguns pré-socráticos até Descartes e pensadores modernos, que encontram na verdade lógica a fundação para uma teoria racional do mundo composta de coisas e de seres cognoscíveis conhecíveis e, portanto, controláveis. Tal tendência filosófica é criticada no interior da Europa por Nietzsche, Heidegger, Foucault, entre outros.

Para os autores associados ao Pensamento Descolonial, a modernidade não existe sem a colonialidade, por isso, em vez de utilizarem a categoria "sistema-mundo moderno", eles preferem falar em "sistema-mundo moderno/colonial". Afirmam que a ciência e o poder colonial formam parte de uma mesma matriz genealógica que se constituiu no século XVI com a formação do sistema-mundo moderno.

Ao problematizar a modernidade a partir da colonialidade, o Pensamento Descolonial distingue-se, portanto, das teorias tradicionais da modernidade. Em primeiro lugar, as origens da modernidade são localizadas na conquista da América e no controle do Atlântico depois de 1492, muito antes do Iluminismo ou do final do século XVIII, como é usualmente aceito. O colonialismo e o desenvolvimento do sistema mundial capitalista são tratados como constitutivos da modernidade, ou seja, a economia 
e suas concomitantes formas de exploração não são ignoradas. Adota-se, dessa forma, em lugar de uma visão da modernidade como um fenômeno intraeuropeu, uma perspectiva planetária em sua explicação. A identificação da dominação de "outros" fora do centro europeu é considerada como uma necessária dimensão da modernidade, com a consequente subalternização do conhecimento desses grupos. Por último, a concepção do eurocentrismo é analisada como a forma do conhecimento da modernidade/ colonialidade, como uma representação hegemônica e um modo de conhecimento que afirma sua própria universalidade (ESCOBAR, 2005).

Dussel (1993, p. 7-15) considera que há dois conceitos de modernidade. O primeiro deles é eurocêntrico, provinciano e regional; a modernidade é uma emancipação da imaturidade por um esforço da razão, tal processo teria ocorrido na Europa, essencialmente no século XVIII. Ao contrário dessa visão, o autor mostra que a modernidade não é produto de fenômenos intraeuropeus, mas uma experiência mundial. A modernidade “[...] aparece quando a Europa se afirma como 'centro' de uma História Mundial que inaugura, e por isso a 'periferia' é a parte de sua própria definição". 4

4 Dussel (2005, p. 64-65) fala em mito da modernidade e o define por meio dos seguintes momentos: "1. A civilização moderna autodescreve-se como mais desenvolvida e superior (o que significa sustentar inconscientemente uma posição eurocêntrica). 2. A superioridade obriga a desenvolver os mais primitivos, bárbaros, rudes, como exigência moral. 3. O caminho de tal processo educativo de desenvolvimento deve ser aquele seguido pela Europa (é, de fato, um desenvolvimento unilinear e à européia o que determina, novamente de modo inconsciente, a 'falácia desenvolvimentista'). 4. Como o bárbaro se opõe ao processo civilizador, a práxis moderna deve exercer em último caso a violência, se necessário for, para destruir os obstáculos dessa modernização (a guerra justa colonial). 5. Esta dominação produz vítimas (de muitas e variadas maneiras), violência que é interpretada como um ato inevitável, e com o sentido quase-ritual de sacrifício; o herói civilizador reveste a suas próprias vítimas da condição de serem holocaustos de um sacrifício salvador (o índio colonizado, o escravo africano, a mulher, a destruição ecológica, etcetera). 6. Para o moderno, o bárbaro tem uma 'culpa' (por opor-se ao processo civilizador) que permite à 'Modernidade' apresentar-se não apenas como inocente mas como 'emancipadora' dessa 'culpa' de suas próprias vítimas. 7. Por último, e pelo caráter 'civilizatório' da 'Modernidade', interpretam-se como inevitáveis os sofrimentos ou sacrifícios (os custos) da 'modernização' dos outros povos 'atrasados' (imaturos), das outras raças escravizáveis, do outro sexo por ser frágil, etcetera.” 
Mignolo (2003, p.74), da mesma forma, relaciona modernidade com colonialidade, pensa o conceito de sistema-mundo como sistema-mundo moderno/colonial Para o autor, a modernidade "[...] leva nos ombros o pesado fardo e a responsabilidade da colonialidade".

[...] o fato é que a economia capitalista mudou de rumo e acelerou seu processo com a emergência do circuito comercial do Atlântico, a transformação da concepção aristotélica da escravidão exigida tanto pelas novas condições históricas quanto pelo tipo humano (por ex.: negro, africano) que se identificou a partir desse momento com a escravidão e estabeleceu novas relações entre raça e trabalho. A partir deste momento, do momento de emergência e consolidação do circuito comercial do Atlântico, já não é possível conceber a modernidade sem a colonialidade, o lado silenciado pela imagem reflexiva que a modernidade (por ex.: os intelectuais, o discurso oficial do Estado) construiu de si mesma e que o discurso pós-moderno criticou do interior da modernidade como auto-imagem do poder. (MIGNOLO, 2005, p. 74-75).

Uma noção-chave para o Pensamento Descolonial é a colonialidade do poder, que permite fazer uma analítica do poder nas sociedades. Indo além da perspectiva de Foucault ${ }^{5}$, Castro-Gómez (2005) considera que o conceito de colonialidade do poder amplia o conceito foucaultiano de poder disciplinar e mostra que os dispositivos panópticos erigidos pelo Estado

5 Foucault (1993, p. 177) constata que no decorrer séculos XVII e XVIII o poder de soberania é substituído gradualmente pelo poder disciplinar, as monarquias soberanas se transformam aos poucos em sociedades disciplinares. O poder disciplinar surge a partir das transformações da sociedade europeia, com o deslocamento de um poder soberano para um corpo burocrático disseminado ao longo do tecido social. Tem como função “[...]'adestrar' as multidões confusas, móveis, inúteis de corpos e forças para uma multiplicidade de elementos individuais". A disciplina busca "fabricar" indivíduos. É "a técnica específica de um poder que toma os indivíduos ao mesmo tempo como objetos e como instrumentos de seu exercício." Foucault (1993) estabelece as características básicas do poder disciplinar. Em primeiro lugar, é uma técnica de distribuição dos indivíduos através da inserção dos corpos em um espaço individualizado, classificatório, combinatório. Em segundo lugar, o poder disciplinar se caracteriza pela distribuição ordenada das atividades dos indivíduos num tempo controlável. Em terceiro lugar, é um instrumento de vigilância. 
moderno inscrevem-se em uma estrutura de caráter mundial, configurada pela relação colonial entre centros e periferias devido à expansão europeia.

A colonialidade do poder pode ser entendida, segundo Quijano (2005, p. 227-228), como a classificação social da população mundial de acordo com a ideia de raça. Diz respeito a uma

[...] construção mental que expressa a experiência básica da dominação colonial e que desde então permeia as dimensões mais importantes do poder mundial, incluindo sua racionalidade específica, o eurocentrismo.

A ideia de raça foi assumida pelos conquistadores como o principal elemento constitutivo, fundacional, das relações de dominação que a conquista exigia. Assim foi classificada a população da América e, posteriormente, do mundo, a partir desse novo padrão de poder.

Trata-se do princípio organizador que estrutura as múltiplas hierarquias do sistema-mundo a partir de centros de poder e de regiões subalternas.

O patriarcado europeu e as noções européias de sexualidade, epistemologia e espiritualidade foram exportadas para o resto do mundo através da expansão colonial, transformadas assim nos critérios hegemônicos que iriam racializar, classificar e patologizar a restante população mundial de acordo com uma hierarquia de raças superiores e inferiores. (GROSFOGUEL, 2008, p. 124).

A perspectiva de superioridade/inferioridade além de estar na base do conceito de superioridade étnica também implica superioridade epistêmica. O conhecimento produzido pelo homem branco é geralmente qualificado como "científico", "objetivo" e "racional", enquanto aquele produzido por homens de cor (ou mulheres) é "mágico", "subjetivo" e "irracional" (DELGADO, 2007). Essa dimensão, a colonialidade do saber, não apenas estabelece o eurocentrismo como perspectiva única de conhecimento, mas também descarta as outras produções intelectuais.

A colonialidade do saber pode ser considerada como um dispositivo que organiza a totalidade do espaço e do tempo de todas as culturas, 
todos os povos e os territórios do planeta, o presente e o passado, em uma grande narrativa universal. Nessa narrativa, a Europa é, ou sempre foi, simultaneamente o centro geográfico e a culminação do movimento temporal (LANDER, 2005). Trata-se de uma hegemonia epistêmica com o poder de nomear, de criar fronteiras, de decidir quais conhecimentos são verdadeiros e quais são falsos e, assim, de estabelecer uma visão de mundo dominante.

Para Castro-Gómez (2005), a Etnografia, a Geografia, a Antropologia, a Paleontologia, a Arqueologia, a História etc., ao estudarem o passado das civilizações, seus produtos culturais e suas instituições, permitiram elaborar comparações e, assim, colaboraram para uma legitimação científica do domínio Europeu sobre o mundo.

Com relação à constituição histórica das disciplinas científicas que se produz na academia ocidental, Lander (2005, p. 33-34) observa dois assuntos fundacionais e essenciais. Em primeiro lugar, "[...] a suposição da existência de um metarrelato universal que leva a todas as culturas e a todos os povos do primitivo e tradicional até o moderno." A partir dessa perspectiva, a sociedade industrial aparece como norma universal e assinala o único futuro possível de todas as outras culturas e povos. Em segundo lugar, as formas do conhecimento desenvolvidas para a compreensão dessa sociedade convertem-se nas únicas formas válidas, objetivas e universais de conhecimento. Como consequência, categorias como: economia, Estado, sociedade civil, mercado, classes, entre outras, transformam-se além de conceitos universais para a análise de qualquer realidade, também em proposições normativas que definem o "dever ser" para todos os povos do planeta.

Estes conhecimentos convertem-se, assim, nos padrões a partir dos quais se podem analisar e detectar as carências, os atrasos, os freios e impactos perversos que se dão como produto do primitivo ou o tradicional em todas as outras sociedades. (LANDER, 2005, p. 33-34).

A legitimação das disciplinas científicas surge sob um ponto de vista supostamente universal, objetivo e deslocalizado. Castro-Gómez (2005) chama de "ponto zero" o imaginário segundo o qual um observa- 
dor do mundo social pode colocar-se em uma plataforma neutra de observação que, por sua vez, não pode ser observada de nenhum ponto. Por isso, o "ponto zero" é o ponto do começo epistemológico absoluto, mas também o do controle econômico-social sobre o mundo. Localizar-se no "ponto zero" equivale a ter o poder de instituir, de representar, de construir uma visão sobre o mundo social e natural reconhecida como legítima e protegida pelo Estado. Diz respeito a uma representação cujos "varões ilustrados" definem-se como observadores neutros e imparciais da realidade (CASTRO-GÓMEZ, 2005).

Uma vez instaladas no "ponto zero", as ciências do homem constroem um discurso sobre a história e a natureza humanas. Os povos colonizados pela Europa aparecem no nível mais baixo da escala de desenvolvimento, enquanto a economia de mercado, a nova ciência e as instituições políticas modernas são apresentadas, respectivamente, como fim último da evolução social, cognitiva e moral da humanidade (CASTRO-GÓMEZ, 2005).

Diferente dos habitantes do "ponto zero", os demais são considerados habitantes do passado. As suas formas de ser, de organização da sociedade e do conhecimento são transformadas não somente em diferentes, mas em "carentes, arcaicas, primitivas, tradicionais, pré-modernas" São colocadas em um momento "anterior" do desenvolvimento histórico da humanidade, ou seja, "[...] aniquilação ou civilização imposta definem, destarte, os únicos destinos possíveis para os outros." (LANDER, 2005, p. 34, grifo do autor).

Ao desqualificar as epistemologias "outras” para inferiorizá-las, o discurso eurocêntrico do "ponto zero" visa construir um mundo de pensamento único. O projeto proposto pelo Pensamento Descolonial implica a descolonialidade, o desenvolvimento de alternativas epistemológicas descoloniais. Isso significa que já não é possível construir a partir de apenas uma epistemologia, um desenho global como "solução única" dos problemas do mundo, seja da esquerda (socialismo, comunismo etc.) ou da direita (desenvolvimentismo, neoliberalismo, democracia liberal etc.). A partir da diversidade epistêmica, há propostas “[...] anticapitalistas, antipatriarcais e anti-imperiais diversas, que apresentam diferentes maneiras 
de enfrentar e solucionar os problemas produzidos pelas relações de poder sexuais, raciais, espirituais, lingüísticas, de gênero e de classe." (GROSFOGUEL, 2007, p. 33). Essa diversidade de propostas de epistemologias "outras" subalternizadas e silenciadas pela epistemologia eurocêntrica significa uma "[...] maneira de transcender a modernidade eurocentrada para além das propostas de culminar na modernidade ou de desenvolver a pós-modernidade." (GROSFOGUEL, 2007, p. 33-34).

Importante para a descolonialidade é o conceito de transmodernidade proposto por Dussel (1993, p. 187). A sua crítica à modernidade não pretende o retorno a um projeto pré-moderno, antimoderno ou pós-moderno, mas sim a efetivação de um projeto de descolonização. A transmodernidade é um "[...] projeto mundial de libertação onde a Alteridade, que era co-essencial da Modernidade, se realize igualmente."

A transmodernidade visa concretizar o inacabado e incompleto projeto da descolonização. Em vez de uma única modernidade, centrada na Europa e imposta ao resto do mundo como um desenho global, Dussel (1993, p. 139) propõe que se enfrente a modernidade eurocentrada por meio de "[...] uma multiplicidade de respostas críticas descoloniais que partam das culturas e lugares epistêmicos subalternos de povos colonizados de todo o mundo."

Dialogando com a noção de transmodernidade, Mignolo (2003, p. 35) desenvolve o conceito de epistemologias de fronteira (pensamento liminar ou pensamento de fronteira). Fala sobre a necessidade da descolonização e da transformação "[...] da rigidez de fronteiras epistêmicas e territoriais estabelecidas e controladas pela colonialidade do poder, durante o processo de construção do sistema mundial colonial/moderno."'6

${ }^{6}$ Nesse espaço das epistemologias de fronteira, cabe salientar o conceito de "Epistemologia do Sul", desenvolvido por Santos (2005). O autor propõe dois caminhos possíveis. O primeiro consiste em analisar que há uma pluralidade interna da ciência. A ciência em geral e as ciências sociais em especial têm uma pluralidade interna enorme: não há apenas uma maneira de fazer ciência, mas várias. O segundo caminho é a pluralidade externa, ou seja, as relações entre ciência e outros saberes - populares, dos camponeses, dos povos urbanos. Saberes da "nossa gente" que de algum jeito a ciência destruiu porque considerou como saberes sem rigor, não eruditos, não formalizados nem institucionalizados. 
As epistemologias de fronteira relacionam-se com o conceito foucaultiano de "insurreição dos saberes sujeitados" (FOUCAULT, 1999). ${ }^{7}$ A intenção de Mignolo (2003) é transportar os saberes sujeitados até os limites da diferença colonial, onde eles se tornam subalternizados na estrutura da colonialidade do poder.

O potencial epistemológico do pensamento liminar de "um outro pensamento" tem a possibilidade de superar a limitação do pensamento territorial (isto é, a epistemologia monotópica da modernidade), cuja vitória foi possibilitada por seu poder de subalternizar o conhecimento localizado fora dos parâmetros das concepções modernas de razão e racionalidade. (MIGNOLO, 2003, p. 103).

O Pensamento Descolonial tem como razão de ser e objetivo a descolonialidade. Esta significa, em um primeiro momento, "epistemologias outras", mas também diz respeito a formas de vidas-outras, economias-outras, teorias políticas-outras.

\section{A Antropologia Jurídica a partir da perspectiva colonial}

A Antropologia, como modelo científico e hegemônico, desenvolveu-se por meio de um objeto específico: as outras sociedades. Estas foram consideradas inicialmente a partir de uma perspectiva evolucionista, isto é, em função do grau de primitivismo comparado às sociedades "avançadas" das quais, obviamente, eram originários os antropólogos.

Sob a aprovação da ciência, a Antropologia, como uma narrativa sobre o "outro", representou um dos instrumentos fundamentais do co-

\footnotetext{
7 Os saberes sujeitados são: “[...] conteúdos históricos que foram sepultados, mascarados em coerências funcionais ou em sistematizações formais." Além disso, podem ser considerados como "[...] uma série de saberes que estavam desqualificados como saberes não conceituais, como saberes insuficientemente elaborados: saberes ingênuos, saberes hierarquicamente inferiores." A "insurreição dos saberes sujeitados", a partir da genealogia, liberta da sujeição os saberes históricos, isto é, "capazes de oposição e de luta contra a coerção de um discurso teórico unitário, formal e científico." Tratase da reativação dos saberes locais e menores contra a hierarquização científica do conhecimento e seus efeitos de poder intrínsecos (FOUCAULT, 1999, p. 11-15).
} 
lonialismo. Entretanto, o saber antropológico até o século XVIII não era denominado "científico", relacionava-se à literatura etnográfica, que incluía relatos de viagens feitos por missionários, viajantes, comerciantes, exploradores, militares, administradores coloniais etc.

A chegada de Colombo à América pode ser considerada como ponto de partida para uma tomada de consciência etnográfica no Ocidente. A conquista e a colonização dos territórios descobertos marcam uma ruptura epistemológica no Ocidente e estabelecem o problema da alteridade, primeiro negando as outras culturas, depois submetendo-as a um processo de apreensão. Tal encontro violento com o "outro" está na origem desse novo uso dos textos históricos e etnográficos europeus que constroem discursos e modos de percepção do "outro" (MIAMPIKA, 2003).

Entre outros discursos nascentes, a Antropologia é um dos mais singulares. Filha da expansão europeia além de suas fronteiras, a Antropologia, primeiro sob a forma de etnografia espontânea, propõe nomear, tratar de compreender, de interpretar, de traduzir ou de transcrever modos de pensar desconhecidos, costumes alheios e diferentes das realidades culturais ocidentais a partir do prisma eurocêntrico de quem nomeia (MIAMPIKA, 2003).

No século XVIII, o eurocentrismo relacionado com o processo de colonização e com a ideologia de civilização ordenava todo discurso antropológico. Nesse sentido, a nascente Antropologia começava a estudar especificamente as sociedades chamadas selvagens, ou primitivas, quer dizer, sociedades consideradas a-históricas e ágrafas. Sem constituir uma ciência legítima autônoma, o discurso etnológico ou antropológico existe primeiro no interior das ideias filosóficas em geral. Esse discurso, no final do século XVIII, passou a levar propriamente o nome de Antropologia $^{8}$ e somente no século XIX passou a ser considerado uma ciência propriamente dita.

8 O termo Antropologia, em seu sentido moderno, foi usado pela primeira vez por Alexandre César Chavannes, professor de Teologia, em seu livro Anthropologie, ou Science Génerale de l'Homme, em 1778. A obra é dividida em nove seções, que vão desde a antropologia física até a etnologia, a psicologia, a linguística e a mitologia (MIAMPIKA, 2003). 
Durante a segunda metade do século XIX, quando a Antropologia estava consolidando-se como ciência e como disciplina acadêmica, sua relação com a jurisprudência era muito estreita ${ }^{9}$ (KROTZ, 2002). Os povos exóticos e seus sistemas jurídicos caíram no campo visual dos investigadores europeus e dos estadunidenses, estes pensaram ter encontrado o material necessário para construção de suas escalas evolutivas (KUPPE: POTZ, 1995).

O debate fundador da Antropologia Jurídica verifica-se nos quadros do evolucionismo social do século XIX. Tal perspectiva teórica caracteriza-se por conferir ao tempo a responsabilidade pelas transformações necessárias. Estas são aceitas como estágios de evolução social. Observa-se que tanto em sua forma erudita quanto popular, a Antropologia abordava culturas e indivíduos colonizados "[...] como versões subdesenvolvidas dos europeus e da sua civilização: eram sinais de primitivismo, representando estágios no caminho da civilização européia." (HARDT; NEGRI, 2001, p. 142).

O século XIX foi o século de consolidação dos impérios coloniais e neste ponto a Antropologia in tervém como o melhor aliado de controle das especificidades culturais dos povos considerados como selvagens e inferiores e, consequentemente, necessitados de civilização. Dessa forma, o discurso antropológico sobre o "outro", a partir da teoria evolucionária da civilização, serviu para confirmar e ratificar a posição "superior" dos europeus e, com isso, legitimar todo o projeto colonialista.

Maldonado-Torres (2006, p. 109) destaca que enquanto a Sociologia, as Ciências Políticas e a Economia encarregavam-se de entender a sociedade moderna, a Antropologia e o Orientalismo direcionavam-se ao estudo das culturas, ou sociedades, não europeias:

O Orientalismo se encarregava de estudar as grandes civilizações do chamado Oriente, enquanto a Antropologia estudava principalmente grupos chamados então 'primitivos' que ainda existiam no mundo.

9 Uma das causas da relação estreita entre antropologia e jurisprudência é que os advogados constituíam, junto com os médicos, um dos grupos profissionais mais numerosos e dos quais surgiram os primeiros especialistas em antropologia: Henry Maine, J.F. McLennan, L.H. Morgan e J.J. Bachofen. 
Desse modo, tanto o Orientalismo quanto a Antropologia contribuíram de forma fundamental para que se pudesse "manejar" as colônias e construir discursos "verdadeiros" sobre os colonizados.

$\mathrm{Na}$ primeira metade do século $\mathrm{XX}$, algumas figuras importantes da Antropologia, como Franz Boas e Bronislaw Malinowski, destacaram-se em sua orientação não evolucionista. Todavia, tais autores compartilhavam um enfoque descritivo, a-histórico, para descrever as relações sociais. O interesse colonialista de conhecer os usos, os costumes e o direito consuetudinário dos povos chamados "primitivos" e "iletrados" estava consoante com uma visão na qual o sistema legal era entendido como uma instituição virtualmente independente e separada de outras instituições da sociedade (MEZARIEGOS, 2005).

Em suma, nas primeiras décadas do século XX, com diferentes nacionalismos e colonialismos operando, os "nativos" eram vistos principalmente por uma perspectiva moderna como povos que precisavam ser conhecidos a fim de propiciar sua integração ao Estado-nação ou a impérios. (RIBEIRO, 2006, p. 150).

Para Kuppe e Potz (1995), essa nova visão da Antropologia Jurídica foi construída a partir de uma concepção etnocêntrica do Direito. As instituições autóctones foram apresentadas como se funcionassem da mesma maneira que a própria ordem jurídica ocidental dos antropólogos, possibilitando que a investigação chegasse sempre ao resultado desejado e encontrasse em cada sociedade o chefe e as estruturas de ordem. Assim, a Antropologia Jurídica descobriu um verdadeiro sistema jurídico, que muito agradava aos interesses da política colonial, em cada sociedade primitiva.

Partia-se do pressuposto que somente algo tão lógico como o Direito Moderno podia ser tão valioso como ele, e cada opinião contrária à premissa de que as sociedades primitivas têm um "verdadeiro sistema jurídico" foi descartada como uma recaída nos erros já superados do evolucionismo. Entretanto, foi justamente o positivismo jurídico que os antropólogos tomaram como método para estudar os povos primitivos e sua cultura jurídica. (KUPPE; POTZ, 1995). 
Com o final da guerra do Vietnam, a "era da inocência" da Antropologia acabou, a relação entre conhecimento e poder tornou-se mais explícita, elaborando novos problemas éticos e políticos. Todos os exóticos e subalternizados precisavam ser vistos como sujeitos de seus próprios $\operatorname{destinos}^{10}$ (RIBEIRO, 2006).

Nesse sentido, vale notar a análise desenvolvida por Sierra e Chenaut (2002), que estabeleceu um histórico das transformações da Antropologia Jurídica anglo-saxã. O primeiro paradigma - normativo - se desenvolveu entre a Primeira e a Segunda Guerra Mundial, tratava-se da discussão e da análise das instituições governadas por normas, dirigidas à manutenção da ordem social (E.E. Evans-Pritchard, Leopold Pospisil, Adamson Hoebel, entre outros). O segundo paradigma - processual - se consolidou após os anos de 1950, tal paradigma concebia os sistemas legais como parte integrante de contextos sociais e culturais particulares (Laura Nader, entre outros). Nos anos de 1980 desenvolveu-se o paradigma da história e do poder, que passou a estudar a maneira como o poder e a história determinam e se inscrevem nos processos legais (Peter Fitzpatrick, entre outros). Já nos anos de 1990, a Antropologia Jurídica anglo-saxã buscou aprofundar o duplo papel da legalidade apontado pelos trabalhos anteriores, de forma que o Direito pode ser ao mesmo tempo um instrumento de dominação e um espaço para resistência (SIERRA; CHENAUT, 2002).

Para Sierra e Chenaut (1992), a Antropologia Jurídica contemporânea, a partir da crítica da visão formalista do Direito, ou seja, da ideia de conceber o legal vinculado ao Direito estatal, impulsionada pelo pluralismo jurídico, resulta de grande interesse para avançar em uma interpretação antropológica sobre os sistemas de regulação vigentes nas distintas sociedades. Surge uma heterogeneidade de abordagens, temas e enfoques que fazem da Antropologia Jurídica mais um campo de investigação dinâmico do que apenas uma disciplina fechada em si mesma.

\footnotetext{
10 Para Ribeiro (2006), a crítica da antropologia tornou-se uma "literatura de angústia" e aprofundou uma das autorrepresentações mais fortes da antropologia, segundo a qual ela se trata de uma disciplina que é filha do imperialismo ocidental, ou de uma disciplina revolucionária que questiona uma suposta superioridade do Ocidente. Esse tipo de crítica foi articulado nas décadas de 1960 e de 1970, principalmente por uma abordagem de economia política marxista e, em geral, em nome das lutas do Terceiro Mundo contra o colonialismo e o imperialismo.
} 


\section{Pensamento Descolonial e Antropologia Jurídica}

Como ficou evidente, no decorrer das considerações históricas, a Antropologia Jurídica sempre se caracterizou pelo estudo da diferença. Todavia, o "outro" foi considerado como um "objeto" a ser analisado a partir dos olhos do antropólogo, o "colonizador". Na atualidade, porém, um potencial de mudança de perspectiva brota no interior dos estudos antropológicos. Surge a possibilidade de realização de pesquisas críticas sobre legalidade a partir de temas como pluralismo e hegemonia jurídica.

É no interior desse quadro que se abre a perspectiva do desenvolvimento de uma Antropologia Jurídica associada ao Pensamento Descolonial. Da mesma forma que a Antropologia foi uma das responsáveis pela discriminação entre pessoas e entre povos, atualmente pode configurar-se como uma ferramenta que possibilita o questionamento dos saberes e, ao mesmo tempo, representa uma alternativa de resgate dos conhecimentos locais, subalternos ou sujeitados.

Entretanto, a Antropologia Jurídica capaz de propiciar um resgate dos saberes subalternos não é aquela que se apresenta como disciplina hegemônica, mas sim como uma reflexão sobre a diversidade humana decorrente da existência de diferentes povos e desenvolvida em várias regiões do mundo. Para Escobar (2005), as antropologias hegemônicas são entendidas como formações discursivas e práticas institucionais associadas à normalização da Antropologia sob as modalidades acadêmicas, principalmente nos Estados Unidos, na Grã-Bretanha e na França. ${ }^{11}$ Apesar de sua diversidade e heterogeneidade, as antropologias hegemônicas

11 Escobar (2005) considera que nas sociedades modernas/coloniais, em síntese, o conhecimento perito constitui uma maneira crucial de configurar e interpretar o mundo. Nesse sentido, as antropologias hegemônicas constituem uma técnica eurocêntrica para a construção e a colonização da "realidade". A especificidade dessas antropologias tem sido a domesticação da alteridade. Enquanto as antropologias hegemônicas visualizam-se co mo paradigmas e são detentoras de uma posição epistêmica privilegiada, elas constituem aparelhos de apagamento das diferenças em nome do estabelecimento e dos cânones antropológicos. Mas isso não significa que ditos cânones sejam homogêneos, inclusive nos centros acadêmicos convencionais da "antropologia anglo-americana", da "etnologia francesa" ou da "antropologia social britânica". Ao contrário, suas condições de existência institucionais e discursivas devem ser entendidas como um equilíbrio instável de lutas permanentes. Assim, há a consolidação de elites acadêmicas e institucionais. 
convergem na tentativa de pôr entre parênteses a historicidade e a especificidade cultural de suas próprias práticas discursiva. Contrapondo-se às antropologias hegemônicas, as antropologias subalternizadas questionam a ideia de uma antropologia única e universal, de forma que adotam uma perspectiva que descentraliza e pluraliza o que tem sido considerado "antropologia" até então.

A visão não hegemônica da Antropologia Jurídica, ao ser associada à perspectiva do Pensamento Descolonial, permite uma avaliação sobre os critérios epistêmicos de produção dos conhecimentos jurídicos vinculados à colonialidade do poder e do saber. Isso ocorre de tal modo que os fundamentos e os pressupostos da cultura jurídica civilizada, antropocêntrica, ocidental e moderna, são devidamente questionados. Torna-se então possível a realização de estudos jurídicos críticos frente a uma compreensão dominante de democracia, Estado, cidadania e justiça, por exemplo.

Nesse sentido, Grosfoguel (2007, p. 32-33) analisa a necessidade de romper com o racismo epistêmico que define os conhecimentos não ocidentais como inferiores aos conhecimentos ocidentais.

Se observarmos o conjunto de pensadores que se valem das disciplinas acadêmicas, vemos que todas as disciplinas, sem exceção, privilegiam os pensadores e teorias ocidentais, sobretudo aquelas dos homens europeus e/ou euro-norte-americanos [...]. O privilégio epistêmico dos brancos foi consagrado e normalizado com a colonização das Américas no final do século XV. Desde renomear o mundo com a cosmologia cristã (Europa, África, Ásia e, mais tarde, América), caracterizando todo conhecimento ou saber não-cristão como produto do demônio, até assumir, a partir de seu provincianismo europeu, que somente pela tradição greco-romana, passando pelo renascimento, o iluminismo e as ciências ocidentais, é que se pode atingir a "verdade" e "universalidade", inferiorizando todas as tradições "outras" (que no século XVI foram caracterizadas como "bárbaras", convertidas no século XIX em "primitivas", no século XX em "subdesenvolvidas" e no início do século XXI em "antidemocráticas"). 
A análise descolonial fornece elementos para refutar formulações teóricas monoculturais e "universais" que posicionam o conhecimento científico ocidental como central, negando assim os saberes locais produzidos a partir de racionalidades sociais e culturais distintas. Tal refutação não implica descartar por completo essa racionalidade, mas sim observar suas pretensões coloniais e imperiais e questionar seu posicionamento como única.

Para Walsh (2007), as ciências não necessitam simplesmente de novos enfoques esquerdistas do pós-marxismo ou do pós-modernismo. O que elas necessitam é de um giro distinto, um giro que parta não da luta de classes, mas sim da luta pela descolonialidade, da constatação da cumplicidade modernidade/colonialidade como marco central que segue organizando e orientando "as ciências" e o pensamento acadêmico-intelectual.

É necessário, portanto, colocar em questão a suposta universalidade do conhecimento científico que impera nas Ciências Sociais e no Direito, na medida em que não captam a diversidade e a riqueza da experiência social nem as alternativas epistemológicas contra-hegemônicas, ou descoloniais, que emergem dessa experiência.

Santos (2002, p. 19) afirma que da escavação histórica, conceitual e semântica emergem " [...] possibilidades de conhecimento para além da ciência moderna, e possibilidades de direito, para além do direito moderno". É no âmbito de tais análises, na crítica dos saberes hegemônicos, que se torna possível uma "insurreição dos saberes sujeitados", uma reativação dos saberes locais e menores contra a hierarquização científica do conhecimento.

Um exemplo interessante é o do antropólogo e representante indígena aymará, Marcelo Fernández Osco, em seu trabalho sobre La ley del Ayllu. Neste estudo, ele trata da justiça nas comunidades aymarás; afirma que o colonialismo jurídico segue mais vivo do que nunca; e desenvolve seu trabalho a partir do qhip nayra (método que implica uma consulta ao passado para que se possa entender a realidade do presente), uma epistemologia aymará que, segundo o autor, permite desconstruir os saberes jurídicos dominantes (FERNANDEZ OSCO, 2005). 
Nesse sentido, é importante o conceito de epistemologias de fronteira. As epistemologias de fronteira subsumem/redefinem a retórica emancipatória da modernidade a partir das cosmologias e das epistemologias do subalterno, localizadas no lado oprimido e explorado da diferença colonial. Elas produzem uma redefinição, para além da modernidade, de conceitos como Estado, cidadania, justiça, direitos humanos, democracia, entre outros. Um bom exemplo, citado por Grosfoguel (2008, p. 138), é a luta Zapatista no México

[...] os zapatistas aceitam a noção de democracia, mas redefinem-na partindo da prática e da cosmologia indígena local, conceptualizando-a de acordo com a máxima "comandar obedecendo" ou "todos diferentes, todos iguais". O que parece ser um slogan paradoxal é, na verdade, uma redefinição crítica descolonial da democracia, recorrendo às práticas, cosmologias e epistemologias do subalterno. Isto leva-nos à questão de como transcender o monólogo imperial estabelecido pela modernidade européia-eurocêntrica.

Os zapatistas, segundo Mignolo (2003, p. 429), “[...] retiraram a democracia do domínio dos projetos globais e a reconverteram às necessidades da história local de Chiapas, onde interage sabedoria indígena e ocidental". Ou seja, onde se considera a diferença colonial e se exerce as epistemologias de fronteira.

O Pensamento Descolonial orienta-se, portanto, para um projeto fragmentado e pluralizado, de forma que há tantas propostas de saberes jurídicos quanto de epistemologias no mundo. Por conseguinte, a Antropologia Jurídica associada à perspectiva descolonial pode ser pensada como um campo capaz de resgatar os saberes jurídicos subalternizados e assim propiciar ao Direito novas práticas e epistemologias "outras", além disso, pode representar um espaço de diálogo entre universidades, movimentos culturais e sociais, organizações e entidades alternativas. 


\section{Considerações Finais}

Neste trabalho, procurou-se demonstrar que a partir do diálogo entre o Pensamento Descolonial e a Antropologia Jurídica surgem novas ferramentas epistemológicas descoloniais, que não somente permitem o questionamento dos saberes jurídicos, mas também representam uma possibilidade de resgate dos conhecimentos subalternizados.

Assim, foram delineados elementos e apontamentos epistemológicos para o desenvolvimento de uma Antropologia Jurídica não hegemônica e plural associada às análises descoloniais.

Inicialmente, foram ressaltadas a importância da crítica à colonialidade no âmbito jurídico e a necessidade de descaracterizar categorias jurídicas coloniais/modernas como neutras e universais, as quais devem ser examinadas criticamente e relacionadas com a análise da colonialidade do poder e do saber.

Sem abordar a questão da epistemologia e do conhecimento não é possível analisar criticamente o Direito, tampouco abrir espaços para outras formas de ser, de pensar, de agir, de julgar e de viver.

Além da crítica, também é preciso avançar no sentido de tornar visíveis epistemologias de fronteira que foram subalternizadas, ou seja, "outras" formas de Estado, de cidadania, de justiça, de direitos humanos, de democracia, que foram relegadas a tradição como exemplos de primitivismo e inferioridade.

Portanto, o estudo da Antropologia Jurídica situado nos múltiplos espaços propiciados pelo Pensamento Descolonial e articulado com os movimentos sociais e culturais, pode colaborar para que saberes silenciados e enterrados pela colonização ocidental agora apareçam nos espaços público e acadêmico. Desse modo, torna-se possível o desenvolvimento de aberturas para pensar os saberes a partir do lado oculto da modernidade, o lado colonial. Corrigir "mentiras" e dizer a "verdade" não é o propósito dessa perspectiva, mas sim representar alternativas para falar sobre "mundos e conhecimentos de outra maneira" e, assim, propiciar o resgate dos saberes jurídicos historicamente subalternizados. 


\section{Referências}

CASTRO-GÓMEZ, Santiago. Ciências sociais, violência epistêmica e o problema da "invenção do outro". In: LANDER, Edgardo (Org.).

A colonialidade do saber. Eurocentrismo e Ciências Sociais. Perspectivas Latino-Americanas. Buenos Aires: CLACSO, 2005.

. La hybris del punto cero. Ciencia, Raza e Ilustración en la Nueva Granada (1750-1816). Bogotá: Pontificia Universidad Javeriana, 2005.

DELGADO, Carolina Santamaría. El bambuco y los saberes mestizos: academia y colonialidad del poder en los estudios musicales latinoamericanos. In: CASTRO-GÓMEZ, Santiago; GROSSFOGUEL, Ramón. El giro decolonial. Reflexiones para una diversidad epistémica más allá del capitalismo global. Bogotá: Siglo del Hombre-Iesco-Pensar, 2007. p. 195-216.

DUSSEL, Enrique. 1492 - O encobrimento do outro. Petrópolis: Vozes, 1993.

. Europa, modernidade, eurocentrismo. In: LANDER, Edgardo (Org.). A colonialidade do saber. Eurocentrismo e Ciências Sociais. Perspectivas Latino-Americanas. Buenos Aires: CLACSO, 2005.

ESCOBAR, Arturo. Más allá del tercer mundo. Globalización y diferencia. Bogotá: Instituto Colombiano de Antropología e Historía, 2005.

FERNANDEZ OSCO, Marcelo. La ley del Ayllu: justicia de acordos. T'inkazos, La Paz, n. 9, p.11-27, jul. 2005.

FOUCAULT, Michel. Vigiar e punir: nascimento da prisão. Tradução de Ligia M. Pondé Vassalo. Petrópolis: Vozes, 1993.

. Em defesa da sociedade: curso no College de France (1975-

1976). Tradução de Maria Ermantina Galvão. São Paulo: Martins Fontes, 1999.

GIDDENS, Anthony. As consequências da modernidade. São Paulo: UNESP, 1991. 
GROSFOGUEL, Ramón. Dilemas dos estudos étnicos norte-americanos: multiculturalismo identitário, colonização disciplinar e epistemologias descoloniais. Ciência e Cultura, São Paulo, v. 59, n. 2, 2007.

Transmodernidade, pensamento de fronteira e colonialidade global. Revista Crítica de Ciências Sociais, Coimbra, n. 80, p. 115-147, mar. 2008.

HABERMAS, Jürgen. O discurso filosófico da modernidade. Lisboa: Dom Quixote, 1990.

HARDT, Michael; NEGRI, Antonio. Império. 2. ed. Rio de Janeiro: Record, 2001.

KROTZ, Esteban. Antropología jurídica: perspectivas socioculturales en el estudio del Derecho. Barcelona: Anthropos, 2002.

KUPPE, René; POTZ, Richard. La antropología del derecho: perspectivas de su pasado, presente y futuro. In: ORDÓÑEZ CIFUENTES, José Emilio Rolando (Coord.). Antropología jurídica, México: UNAM, 1995. p. 9-45.

LANDER, Edgardo. Ciências sociais: saberes coloniais e eurocêntricos. In: LANDER, Edgardo (Org.). A colonialidade do saber. Eurocentrismo e Ciências Sociais. Perspectivas Latino-Americanas. Buenos Aires: CLACSO, 2005.

MALDONADO-TORRES, Nelson. Pensamento crítico desde a subalternidade: os estudos étnicos como ciências descoloniais ou para a transformação das humanidades e das ciências sociais no século XXI. Afro-Ásia, n. 34, Bahia, p. 105-129, 2006.

. Sobre la colonialidad del ser: contribuciones al desarrollo de un concepto. In: CASTRO-GÓMEZ, Santiago; GROSFOGUEL, Ramón. El giro decolonial. Reflexiones para una diversidad epistémica más allá del capitalismo global. Bogotá: Siglo del Hombre-Iesco-Pensar, 2007. p. 128-168. 
MEZARIEGOS, Carlos Salvador Ordóñez. Pluralismo Jurídico: una aproximación antropológica desde los altos de Guatemala. In: CIFUENTES, José Emilio Rolando Ordóñez (coord). Pluralismo jurídico y pueblos indígenas: XIII Jornadas Lascasianas Internacionales. Mexico: Universidad Nacional Autónoma, 2005, p. 223-241.

MIAMPIKA, Landry-Wilfrid. De la invención del otro a las travesías transculturales postcoloniales. In: SÁNCHEZ, José A.; HERNÁNDEZ, José A. Gómez. Práctica artística y políticas culturales: algunas propuestas desde la Universidad. Murcia: Servicio de Publicaciones, Universidad de Murcia, 2003. p. 81-102.

MIGNOLO, Walter. Histórias locais/ projetos globais: colonialidade, saberes subalternos e pensamento liminar. Belo Horizonte: UFMG, 2003.

. Europa, modernidade e eurocentrismo. In: LANDER, Edgardo (Org.). A colonialidade do saber. Eurocentrismo e Ciências Sociais. Perspectivas Latino-Americanas. Buenos Aires: CLACSO, 2005.

QUIJANO, Aníbal. Colonialidade do poder, eurocentrismo e América Latina. In: LANDER, Edgardo (Org.). A colonialidade do saber. Eurocentrismo e Ciências Sociais. Perspectivas Latino-Americanas. Buenos Aires: CLACSO, 2005.

RIBEIRO, Gustavo Lins. Antropologias mundiais: para um novo cenário global na antropologia. Revista Brasileira de Ciências Sociais, São Paulo, v. 21, n. 60, 2006.

SANTOS, Boaventura de Sousa. A crítica da razão indolente: contra o desperdício da experiência. 4. ed. São Paulo: Cortez, 2002. 1 v. (Coleção Para um novo senso comum: a ciência e a política na transição paradigmática).

. Hay que reinventar la Universidad como tenemos que reinventar las ciencias sociales. Gaceta. México, n. 91-93, jul./set. 2005. Disponível em: <http://www.uv.mx/gaceta/Gaceta91/91/mar/Mar2.htm>. Acesso em: 18 mar. 2008. 
SIERRA, María Teresa; CHENAUT, Victoria. El campo de investigación de la antropología jurídica. Nueva Antropología, México, v. 13, n. 43, nov. 1992.

. Los debates recientes y actuales en la antropología jurídica: las corrientes anglosajonas. In: KROTZ, Esteban. Antropología jurídica: Perspectivas socioculturales en el estudio del Derecho. Barcelona: Anthropos, 2002.

WALSH, Catherine. ¿Son posibles unas ciencias sociales/culturales otras? Reflexiones en torno a las epistemologías decoloniales. Nómadas. Revista Crítica de Ciencias Sociales y Jurídicas. Editorial. Teorías decoloniales en América Latina. Universidad Central - Colombia. Colombia, n. 26, abr. 2007.

Recebido em: 20/09/2010 Revisado em: 24/11/2010 Aprovado em: 01/12/2010 